\title{
A experiência do acolhimento integrado no ambulatório de diabetes do Hospital Universitário- CAS da Universidade Federal de Juiz de Fora (HU-UFJF)
}

\author{
Bruno Feital Barbosa Motta, Mônica Barros Costa, Antônio Paulo André de Castro, Maria Stella \\ Tavares Filgueiras
}

\begin{abstract}
Resumo
Melhorar a qualidade dos serviços de saúde tem se mostrado um grande desafio na consolidação da melhora do Sistema Único de Saúde. Preocupados com essa realidade e orientados pela Política Nacional de Humanização (PNH), os trabalhadores (acadêmicos, residentes e profissionais de saúde) do Ambulatório de Diabetes do Hospital Universitário- CAS da Universidade Federal de Juiz de Fora (HU-UFJF) implantaram o projeto de Acolhimento Integrado no serviço. O presente trabalho tem como objetivo apresentar o relato da experiência de operacionalização do projeto de Acolhimento Integrado executado pelos trabalhadores de saúde do Ambulatório de Diabetes do HUUFJF. Trata-se de um estudo observacional, descritivo, onde os pesquisadores atuaram como participantes observadores, para realização do relato de experiência, de abordagem qualitativa e objetivo exploratório. No que diz respeito a delimitação temporal desse trabalho, buscamos descrever o funcionamento do Acolhimento Integrado desenvolvido no Ambulatório de Diabetes durante o período de setembro de 2009 a janeiro de 2014. A implantação do Acolhimento Integrado se concretizou após a criação de um grupo de discussão interdisciplinar, formado pelos trabalhadores do serviço, que abordou temas como acolhimento, integralidade e saúde coletiva. A operacionalização desse projeto resultou na modificação da estrutura médico- centrada para usuário- centrada. Essa mudança aumentou e qualificou os espaços de interseção entre trabalhadores de saúde e usuários, fortalecendo os vínculos e a co-responsabilização no tratamento. Minimizando a centralização dos processos de produção de saúde da figura do médico, verificou-se a reorganização do serviço com a alteração do fluxo de atendimento e ampliação do acesso às demais especialidades do Ambulatório, a saber Educação Física, Farmácia, Enfermagem, Nutrição, Odontologia, Psicologia e Serviço Social, gerando maior aproveitamento desses trabalhadores. Além disso, o acolhimento organizou o fluxo de trocas de informações entre as áreas que compunham o Ambulatório de Diabetes ampliando a interdisciplinaridade e a integralidade das ações de saúde do serviço. Identificamos que a experiência da implementação do acolhimento na atenção secundária, em específico no Ambulatório de Diabetes do HU-UFJF, foi exitosa tendo em vista a observância de seu impacto na organização da equipe e na produção do cuidado em saúde de forma mais integrada. Entendemos que essa é uma experiência que pode ser replicada em outros espaços de saúde, desde que respeitadas suas especificidades. Contudo, o Acolhimento não pode ser identificado como a solução para todos os problemas de um serviço de saúde. Pelo contrário, ele é o primeiro passo para mudanças significativas nas práticas de produção de saúde que devem ser constantemente reavaliadas.
\end{abstract}

Descritores: Acolhimento, Integralidade, Diabetes Mellitus 